Molecular weight tuning of low bandgap polymers by continuous flow chemistry: increasing the applicability of PffBT4T for organic photovoltaics Peer-reviewed author version

PIROTTE, Geert; Agarkar, Shruti; Xu, Bing; Zhang, Junxiang; LUTSEN, Laurence; VANDERZANDE, Dirk; Yan, He; Pollet, Pamela; Reynolds, John R.; MAES, Wouter \& Marder, Seth R. (2017) Molecular weight tuning of low bandgap polymers by continuous flow chemistry: increasing the applicability of PffBT4T for organic photovoltaics. In: JOURNAL OF MATERIALS CHEMISTRY A, 5(34), p. 18166-18175.

DOI: $10.1039 / \mathrm{c} 7 \mathrm{ta} 05627 \mathrm{c}$

Handle: http://hdl.handle.net/1942/24975 


\section{Molecular weight tuning of low bandgap polymers by continuous flow chemistry: increasing the applicability of PffBT4T for organic photovoltaics $\dagger$}

Geert Pirotte ${ }^{a}$, Shruti Agarkar ${ }^{b}$, Bing X $u^{b}$, Junxiang Zhang ${ }^{b}$, Laurence Lutsen ${ }^{c}$, Dirk Vanderzande ${ }^{a, c}$, He Yan ${ }^{d, e}$, Pamela Pollet ${ }^{b}$, John R. Reynolds ${ }^{b *}$, Wouter Maes ${ }^{a, c} *$, Seth R. Marder ${ }^{b} *$

(a) UHasselt - Hasselt University, Institute for Materials Research (IMO-IMOMEC), Design \& Synthesis of Organic Semiconductors (DSOS), Agoralaan - Building D, 3590 Diepenbeek, Belgium

(b) School of Chemistry \& Biochemistry and Center for Organic Photonics and Electronics, Georgia Institute of Technology, 901 Atlantic Drive, Atlanta, Georgia 30332, United States

(c) IMEC, IMOMEC, Universitaire Campus - Wetenschapspark 1, 3590 Diepenbeek, Belgium

(d) Department of Chemistry, The Hong Kong University of Science and Technology, Clear Water Bay, Kowloon, Hong Kong

(e) HKUST-Shenzhen Research Institute, No. 9 Yuexing 1st RD, Hi-tech Park, Nanshan, Shenzhen 518057, China

Corresponding authors:

Tel.: +1 4043854390; E-mail: reynolds@ chemistry.gatech.edu

Tel.: +32 11268312; E-mail: wouter.maes@uhasselt.be

Tel.: +1 4043856048; E-mail: seth.marder@chemistry.gatech.edu

ORCIDs:

G. Pirotte: 0000-0001-9829-4569

D. Vanderzande: 0000-0002-9110-124X

P. Pollet: 0000-0002-7416-4193

H. Yan: 0000-0003-1780-8308

J. R. Reynolds: 0000-0002-7417-4869

W. Maes: 0000-0001-7883-3393

† Electronic supplementary information (ESI) available (flow and processing equipment, active layer pictures, $J-V$ curves, and flow parameters, GPC data of the resulting polymer samples, and representative ${ }^{1} \mathrm{H}$ NMR spectra and GPC traces of the PffBT4T polymers). See DOI: $10.1039 / \ldots$ 


\begin{abstract}
Continuous flow chemistry has been shown to be a suitable method for the large-scale preparation of conjugated polymers with uniform structural and macromolecular characteristics, which is especially relevant when applying these materials in optoelectronic devices. The molecular weight and dispersity of conjugated polymers have a major effect on final device performance through a combination of processing and morphological considerations. In this work, the low bandgap polymer PffBT4T-2OD ('PCE-11'), which provides highly efficient bulk heterojunction solar cells, is synthesized by continuous flow chemistry using an easily mountable home-made apparatus. The influence of various reaction parameters on the material characteristics is investigated. Particular attention is devoted to tuning of the molecular weight, as this has a major impact on solubility and processability of the resultant polymer and, ultimately, solar cell performance. We find that temperature, monomer concentration, and injection volume of the polymerization mixture are significant parameters that can be used to optimize the control over molecular weight. The same protocol is then also applied to a structurally similar polymer with longer alkyl side chains, PffBT4T-2DT, affording important advantages in terms of processing due to its higher solubility. An average power conversion efficiency of $9.4 \%$ for bulk heterojunction solar cells using $\mathrm{PC}_{71} \mathrm{BM}$ as the acceptor phase is achieved based on this flow-synthesized polymer.
\end{abstract}




\section{Introduction}

Over the past decade, bulk heterojunction (BHJ) organic photovoltaic (OPV) devices have received significant interest as potential renewable energy sources. Organic thin-films provide flexibility, tunable absorption profiles, and the ability to be printed. For these reasons OPV devices can be particularly attractive for portable and/or wearable consumer goods, building or automotive integration, and partial replacement of conventional power sources. ${ }^{1,2}$ Several material combinations of electron donor polymers and acceptors affording power conversion efficiencies (PCEs) over 10\% in solution processed (single-layer) BHJ devices have been reported, with further improvements still on the horizon, in particular for fullerene-free (so called non-fullerene) OPVs. ${ }^{3-11}$ Along with higher efficiency and improved lifetime, upscaling of OPV technology in both materials preparation and processing is crucial if this technology is to become commercially relevant. Two major aspects are currently hampering the implementation of polymer-based solar cells in large area modules for industrial and domestic energy production, along with commercially viable niche products such as wearable electronics and portable energy sources. Firstly, there is a notable lack in the availability of large quantities (gram to kilogram scale) of high-quality photoactive polymers with uniform characteristics. Most low bandgap polymers are synthesized on a lab scale (maximum several hundreds of milligrams) and batch-to-batch variations must be avoided when moving to a production process. Secondly, most reports simply mention optimized solar cell efficiencies for spin-coated devices and the translation of these results to a large area printing facility (e.g. roll-to-roll, $R 2 \mathrm{R}^{12-14}$ ) is generally not performed, although this is required to push OPV to the market. Both the conventional synthesis and processing procedures thus lack the intrinsic character of being easily scalable and these aspects urgently need to be addressed by the research community.

Unfortunately, batch chemistry protocols for the synthesis of (push-pull type) conjugated polymers have a limited upscaling capacity. ${ }^{15}$ Flow chemistry has several advantages over batch, which includes (i) superior mixing, (ii) precise control on reagent addition, and (iii) enhanced heat transfer, which minimizes the number of hotspots during reaction and also allows precise control over the temperature. ${ }^{16-21}$ As the reaction kinetics and viscosity of the reaction mixture are highly temperature dependent, it is particularly interesting to synthesize these polymers via flow, as this will minimize batch-to-batch variations due to fluctuations in temperature. In order for OPV to become an industrially relevant technology, the active materials will ultimately need to be synthesized on a large scale, which goes well beyond the laboratory scale typically employed. Using flow chemistry methods, larger quantities of material can easily be made by longer operation times without altering the reaction conditions. Production rates can be further enhanced by increasing the reactor length or by parallelization of multiple set-ups. ${ }^{22-28}$ With the latter approach, the operator scales out the entire process rather than scaling it up. This has the advantage that the reaction conditions do not have to be optimized again and the safety risks are similar, which is for conventional upscaling frequently not the case.

Continuous flow chemistry has emerged as a versatile and readily accessible technology for the preparation of organic semiconductors. Over the past couple of years, several reports have been published on the flow synthesis of conjugated polymers via Kumada, Stille, and Suzuki cross-coupling approaches. ${ }^{15,28-33}$ In addition to the use of these conventional coupling reactions, also direct arylation polymerization has been deployed in flow. ${ }^{34}$ Continuous flow chemistry has thus created an accessible platform for the production of conjugated polymers on a gram scale. Moreover, the flow-synthesized polymers have shown a high reproducibility from batch-to-batch with respect to the final PCE in solar cell devices (with absolute differences $<0.5 \%$ ). ${ }^{15,31}$ 
There are multiple parameters that influence the efficiency of BHJ polymer solar cells. One of them, which finds its origin in the synthesis process, is the molecular weight of the deployed electron donor polymer. ${ }^{35-40}$ It is rather difficult to define an optimal molecular weight as it influences multiple parameters simultaneously in both a positive and negative manner. High molecular weights have been shown to enhance the charge carrier mobility, photoactivity, and electrode surface interfacial ordering of the polymer. ${ }^{41-46}$ On the other hand, the molecular weight also strongly influences the solubility of the polymer which is, together with its miscibility with the acceptor material, a key feature in achieving the desired 'intimately mixed' BHJ blend. Too high molecular weights can lead to materials that are not sufficiently soluble within the experimental window of device processing, and can cause large domain sizes to form during phase separation with the acceptor. With the latter type of morphology, a significant number of excitons will be generated in the bulk of the donor material, at distances larger than the exciton diffusion length from the acceptor phase. These excitons are more likely to decay before they reach the interface where charge separation can occur.

Although it has been shown that flow chemistry can effectively be used for the continuous production of OPV donor polymers, ${ }^{15,31}$ little investigation has been done on controlling the process itself. In this work, we elaborate on the influence of different parameters of the flow process, including monomer concentration, temperature, and reaction volume, on the final molecular weight of the produced polymer. For this purpose, the low bandgap donor polymer PffBT4T-2OD [poly[(5,6-difluoro-2,1,3benzothiadiazol-4,7-diyl)-alt-(3,3"',-di(2-octyldodecyl)-2,2';5',2";5",2"',-quaterthiophen-5,5-diyl)], so called 'PCE11'; Scheme 1] was chosen, as it provides one of the highest PCEs in the field $(>10 \%$ with multiple fullerene derivatives), while being prepared from relatively easy to synthesize monomers. ${ }^{3,47}$ The high PCE is attributed to the strong temperature-dependent aggregation property of the polymer, which heavily depends on the molecular weight. ${ }^{3} \mathrm{~A}$ specific synthetic protocol that allows for the controlled preparation of specific molecular weights of PffBT4T-2OD has not been reported, but will be especially useful in active material and device development and optimization. Based on the evaluation of commercially available PffBT4T-2OD, specific number-average molecular weights $\left(M_{\mathrm{n}}\right)$ between 40 and $60 \mathrm{kDa}$ were targeted. Batch-based protocols delivered molecular weights ranging from 36 to $85 \mathrm{kDa}$ with batch-to-batch variations up to $9 \mathrm{kDa}$. Polymers synthesized by flow chemistry displayed an accessible molecular weight range from 26 up to $55 \mathrm{kDa}$. The controlled flow polymerization was investigated as a function of (i) temperature, (ii) residence time, (iii) injection volume, and (iv) concentration, specifically with regard to the molecular weight of the polymeric product. The highest control over the molecular weight was achieved by variation of the reaction concentration.

Lastly, an optimized synthetic flow protocol was applied for the synthesis of the analogous polymer PffBT4T-2DT (poly[(5,6-difluoro-2,1,3-benzothiadiazol-4,7-diyl)-alt-(3,3'"'-di(2-decyltetradecyl)2,2';5',2";5",2",'-quaterthiophen-5,5-diyl)]; Scheme 1) with longer alkyl side chains (decyltetradecyl as opposed to octyldodecyl). Combination of this polymer with the non-fullerene acceptor IDTBR has been shown to afford similar efficiencies as PffBT4T-2OD $( \pm 10 \%) .{ }^{9}$ The flow-synthesized polymer has a similar molecular weight as its PffBT4T-2OD analogue and combination with $\mathrm{PC}_{71} \mathrm{BM}$ in organic solar devices gave PCEs up to $9.8 \%$.

\section{Results and discussion}

\subsection{Commercially available PffBT4T-2OD}

PffBT4T-2OD was initially purchased from two independent suppliers. To evaluate the material quality of the two polymer samples, BHJ OPV devices were fabricated following the protocols 
provided by the suppliers. The devices were constructed using the inverted architecture glass/ITO/ZnO/PffBT4T-2OD:PC ${ }_{71} \mathrm{BM} / \mathrm{MoO}_{3} / \mathrm{Ag}$. The active layer blend (PffBT4T-2OD:PC ${ }_{71} \mathrm{BM}$ ) was prepared in a $1: 1.2$ ratio (wt/wt $\%$ ) with a total concentration of 7.5 and $5.5 \mathrm{mg} / \mathrm{mL}$ for the first and second supplier, respectively, and the optimal solvent mixture chlorobenzene:o-dichlorobenzene 1:1 with 3\% diiodooctane (DIO). Before spin-coating, both the active layer solution and the substrate were heated to $110{ }^{\circ} \mathrm{C}$. During the deposition of the active layer blend, major differences between the two polymer batches were observed. The first commercial material afforded uniform films, whereas the active layer solution from the second polymer batch immediately formed a gel upon contact with the substrate. Due to this gel formation, the active layer solution loses its capability to spread out evenly over the substrate during spin coating and remains accumulated where it has been deposited (see Figure S4a). Both samples were analysed by gel permeation chromatography (GPC) at $140{ }^{\circ} \mathrm{C}$ with 1,2,4-trichlorobenzene as the eluent, exhibiting number-average molecular weights of $41.8 \mathrm{kDa}$ $(\nexists 1.7)$ and $57.2 \mathrm{kDa}(\nexists 2.3)$ for the first and second material, respectively. It should be noted that the elevated temperature is necessary for solubilizing the polymer completely and to achieve a reliable estimate of the molecular weight. The difference in molecular weight of $\sim 15 \mathrm{kDa}$ seemingly lead to a significant difference in solubility of the polymers, with the sample from the first commercial supplier almost completely soluble in hot chloroform ( $>95 \mathrm{wt} \%$ collected by soxhlet extraction), whereas the second sample displayed almost no solubility in hot chloroform. Complete dissolution of sample 2 was only achieved by using hot chlorobenzene (quantitative collection by soxhlet extraction).

Processing of the second commercial sample required a technical modification of our standard spincoating protocols. In the initial protocol, the heated glass substrate was put on a room temperature metallic chuck surface of the spin-coater, likely resulting in the polymer solution cooling rapidly, leading to gelation of the active layer solution and incomplete coverage of the substrate (Figure S4-a). With a modification of the chuck (the substrate was put in an elevated position to minimize contact with the metal surface, Figure S3), the processing could be performed at a higher substrate temperature. This adapted protocol allowed for proper film formation of the higher molecular weight PffBT4T-2OD from the second supplier, similar as films produced by the initial processing set-up for lower molecular weight PffBT4T-2OD (Figure S4-b).

The PffBT4T-2OD sample from the first commercial supplier, with the lower molecular weight, reached an average PCE of $9.8 \%$, with a maximum of $10.1 \%$ (Table 5, entry 1). The higher molecular weight PffBT4T-2OD from the second supplier afforded a significantly lower average PCE of $8.4 \%$, although it displayed a similar maximum PCE of $9.9 \%$ (Table 5, entry 2). We attribute the lower average value to the solubility difference between the two materials, leading to increased difficultly in obtaining reproducible results with the higher molecular weight sample in our hands. For these reasons, we were motivated to carry out a careful synthetic flow study to examine molecular weight control in these PffBT4T-2OD materials.

\subsection{Batch polymerization}

A careful evaluation of the batch process prior to developing a flow synthesis protocol is essential, as it provides important information concerning the solubility of the reaction components (monomers, polymer, catalyst, and intermediates), viscosity, kinetics, etc. Therefore, PffBT4T-2OD was first synthesized by a standard batch Stille polycondensation (Scheme 1). 


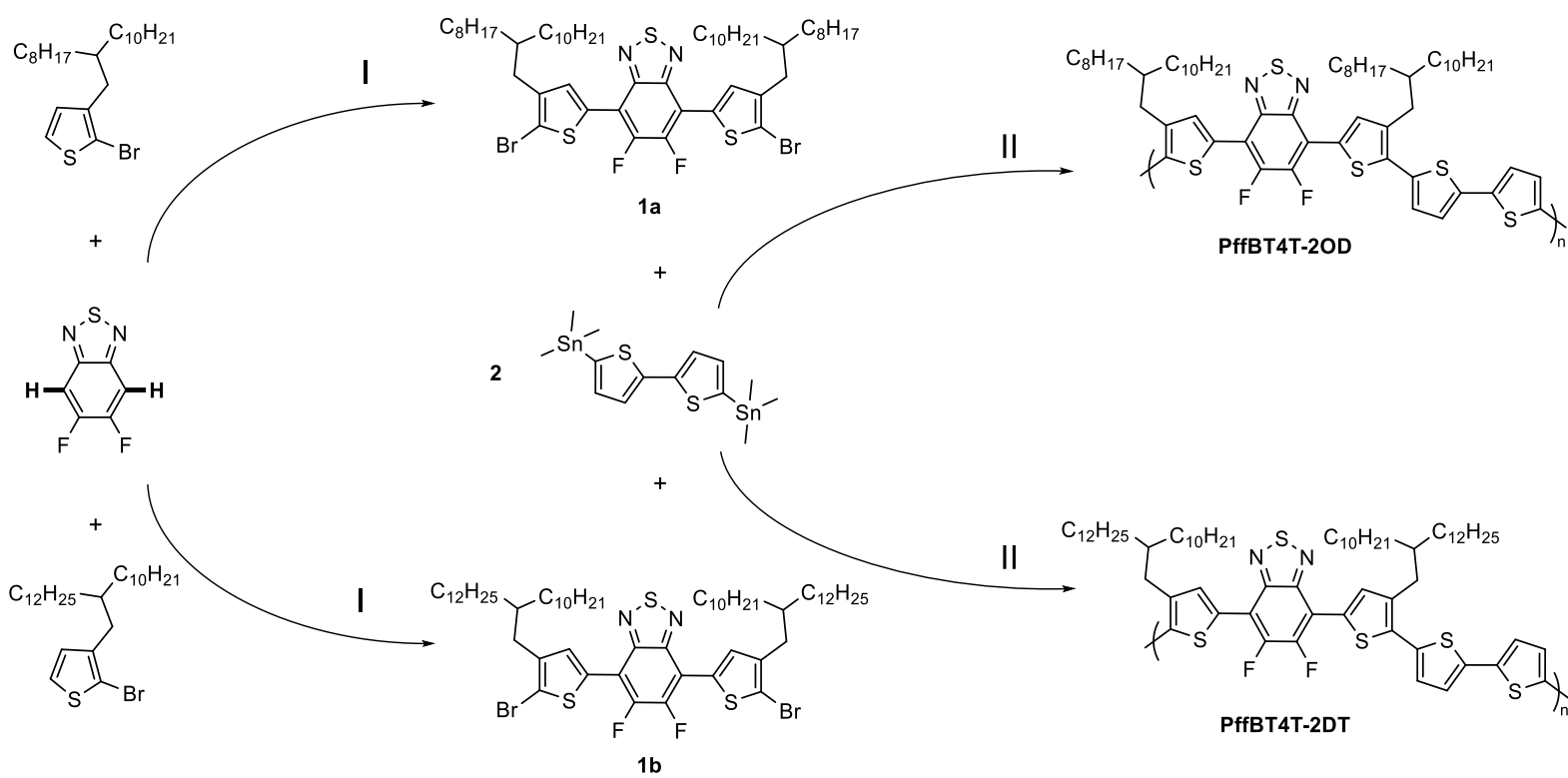

Scheme 1: Synthesis of the bisthiophene-benzothiadiazole monomers by dehydrogenative cross-coupling, followed by the Stille polycondensation reaction yielding the PffBT4T-2OD and PffBT4T-2DT polymers (I. Pd(OAc)2, AgOPiv, DMSO, 80 ${ }^{\circ} \mathrm{C}, 20$ h; II. $\mathrm{Pd}_{2}(\mathrm{dba})_{3}, \mathrm{P}(o \text {-tol })_{3}$, chlorobenzene $)$.

The required stannylated monomer, 5,5'-bis(trimethylstannyl)-2,2'-bithiophene (2), was prepared by a literature $\quad$ procedure. ${ }^{48}$ 4,7-Bis(5-bromo-4-(2-octyldodecyl)thiophen-2-yl)-5,6difluorobenzo[c][1,2,5]thiadiazole (1a) was synthesized by dehydrogenative cross-coupling (Scheme 1) ${ }^{49-51}$ Dehydrogenative cross-coupling and other types of direct arylation protocols have recently received an increased attention as they eliminate the need for toxic intermediates. ${ }^{52-56}$ The direct arylation protocol allows the preparation of monomer $1 \mathrm{a}$ in $60 \%$ yield and employs two reaction steps less than the commonly used Stille cross-coupling approach. ${ }^{3}$ This significantly simplifies the 'synthetic complexity' for the preparation of the monomers, classifying PffBT4T-2OD and derivatives, combined with their high efficiency, as potentially industrially viable candidates for solar cell applications. ${ }^{57}$

To gain some basic insight into the kinetics of the batch polymerization process, five polymerizations were conducted and analysed as a function of time (Table 1). Experimentally, the monomer concentration was chosen to be $376 \mathrm{mM}$ and the polymer samples were purified by soxhlet extractions with methanol, hexanes, dichloromethane, and chloroform, and then finally collected with chlorobenzene. The initial rate of the Stille cross-coupling is relatively high, as an average molecular weight of $36 \mathrm{kDa}$ is already reached within one hour (entry 1). In comparison to the polymerizations run over a longer time (entry $2-5$ ), one can see that $80 \%$ or more of the time is used for making the final couplings leading to higher molecular weights. This behaviour is expected as the increase of the chain length leads to a decrease in active group concentration and can also increase the viscosity, both of which can lead to to a decreased reaction rate. ${ }^{58-60}$ This latter behaviour is intrinsic to polycondensation reactions. The end phase of the polymerization lies between 6 and 12 hours (entry 24). Beyond that point (entry 3-5), the final $M_{\mathrm{n}}$ reaches a plateau at about $80 \mathrm{kDa}$ within experimental error. In our hands, batch chemistry was effectively used on a lab scale to synthesize PffBT4T-2OD with high molecular weights ranging from 75 to $85 \mathrm{kDa}$, but did not provide the fine degree of control we require to obtain polymer of optimum molecular weight for processing and device fabrication.

Table 1: Number average molecular weights of the PffBT4T-2OD polymers synthesized in batch as a function of polymerization time. $^{\mathrm{a}}$

\begin{tabular}{l|l|l|l}
\hline Entry & Reaction time (h) & $M_{\mathbf{n}}(\mathrm{kDa})$ & $\boldsymbol{D}$ \\
\hline
\end{tabular}




\begin{tabular}{c|c|c|c}
\hline $1^{\mathrm{b}}$ & 1 & 36.0 & 1.8 \\
2 & 6 & 64.3 & 1.8 \\
3 & 12 & 82.2 & 1.8 \\
4 & 24 & 75.0 & 1.8 \\
5 & 72 & 84.2 & 2.1 \\
\hline
\end{tabular}

a All reactions were performed at $145{ }^{\circ} \mathrm{C}$ with a monomer concentration of $376 \mathrm{mM}$ and a catalyst loading of $0.5 \mathrm{~mol} \%$.

${ }^{\mathrm{b}}$ Due to the lower $M_{\mathrm{n}}$, the polymer was collected quantitatively with chloroform.

\subsection{Flow polymerization}

\subsubsection{Flow polymerization set-up}

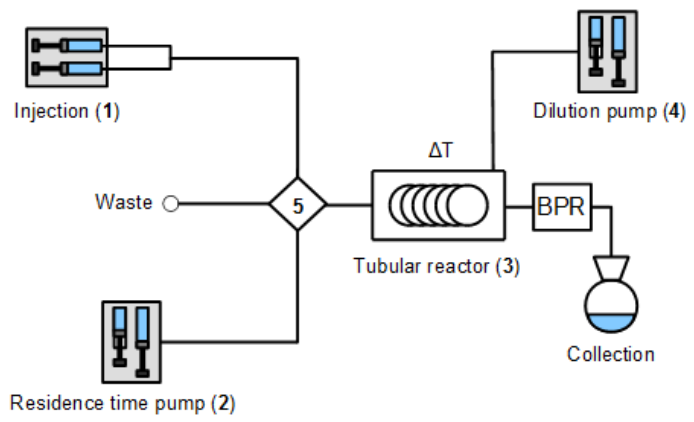

Figure 1: Graphical representation of the continuous flow set-up.

Given the limitations that were uncovered in the batch polymerization, we then investigated the influence of different reaction parameters, both physical and chemical, on the molecular weight of the PffBT4T-2OD polymer as prepared using flow polymerization methods. As the processability of higher molecular weight samples is limited, molecular weights below $60 \mathrm{kDa}$ were targeted, simultaneously limiting the risk of over-pressurizing the system due to increased viscosity. All flow experiments were conducted on a custom-designed flow reactor apparatus (Figure 1, S1, S2), taking the strong temperature-dependent solubility of PffBT4T-2OD into account (as the polymer can only be completely dissolved in chlorobenzene at temperatures above $80-90^{\circ} \mathrm{C}$ ). Three reaction temperatures of 120,130 and $140{ }^{\circ} \mathrm{C}$ were employed. As these temperatures are close to the boiling point of chlorobenzene $\left(131{ }^{\circ} \mathrm{C}\right)$, the reaction solvent, the system was pressurized to 40 psi with a back pressure regulator (BPR) to avoid the formation of gas bubbles inside the system, which would lead to an irregular flow and thereby a non-uniform residence time. The flow reactor was designed to account for viscosity changes, application of a wide range of flow rates, and accurate temperature control. The reactor volume was chosen to be sufficiently large $(20 \mathrm{~mL})$ to allow for an acceptable flow rate at different residence times, for which cooling of the reaction mixture is sufficiently slow, such that no accumulation of polymer material or gelation occurs upon collection. The reaction mixture was diluted 1:1 immediately before exiting the reactor. Diethylammonium diethyldithiocarbamate was added to the dilution stream to facilitate catalyst removal upon purification. ${ }^{31}$ The polymers were collected by precipitation in methanol. Prior to GPC analysis, the polymers were purified by consecutive soxhlet extractions with methanol, hexanes, and dichloromethane. The polymer samples were then finally collected with chlorobenzene and precipitated again in methanol.

\subsubsection{Influence of experimental parameters}

\section{Temperature}


To monitor the effect of temperature on the molecular weight of PffBT4T-2OD, three reaction temperatures - 120,130 , and $140{ }^{\circ} \mathrm{C}$ - were investigated. For consistency, the polymers were produced from the same stock solution for each temperature experiment. The overall residence time was chosen to be 30 minutes and the injected volume for each polymer was approximately $1.75 \mathrm{~mL}$, yielding $30-40 \mathrm{mg}$ of polymer.

As for most reactions, at first glance, one would expect the reaction rate of the Stille polycondensation to increase with increased temperature and this increase in rate would lead to an increase in the molecular weight of the polymer, prior to events leading to a saturation of the molecular weight. However, for these experiments the opposite effect was observed (Table 2, entries 1a-c). An increase of the temperature by $10{ }^{\circ} \mathrm{C}$ reduced the molecular weight by approximately $10 \mathrm{kDa}$. Since the batch experiments were conducted at a temperature of $145^{\circ} \mathrm{C}$, degradation of the monomers or catalyst was considered to be unlikely. To verify that degradation neither takes place in the separate monomer and catalyst solutions before injection, as there is a significant time span between the injections, the experiment was also performed in the reversed order (entries $2 \mathrm{a}-2 \mathrm{c}$ ). As the $130{ }^{\circ} \mathrm{C}$ experiment is always done as the second injection, a third experiment (entry 3 ) was used to independently determine the molecular weight at this temperature. From the results that were obtained, it is clear that the molecular weights are comparable, irregardless of the order of injection or the time between the preparation of the solution and the actual injection.

Table 2: Number-average molecular weights of the PffBT4T-2OD polymers synthesized in flow at different temperatures. ${ }^{\text {a }}$

\begin{tabular}{c|c|c|c}
\hline Entry & $\boldsymbol{T}\left({ }^{\circ} \mathbf{C}\right)$ & $\boldsymbol{M}_{\mathbf{n}}(\mathbf{k D a})$ & $\boldsymbol{D}$ \\
\hline 1a & 120 & 48.6 & 2.1 \\
1b & 130 & 39.9 & 1.9 \\
1c & 140 & 30.9 & 1.8 \\
2a & 140 & 31.9 & 2.0 \\
2b & 130 & 39.3 & 2.0 \\
2c & 120 & 45.0 & 2.1 \\
3 & 130 & 40.4 & 1.9 \\
\hline
\end{tabular}

${ }^{a}$ An overall flow rate of $666 \mu \mathrm{L} / \mathrm{min}$ and a monomer concentration of $59.2 \mathrm{mM}$ were used.

Before and after injection, the feed of the reactor exists out of pure solvent. This creates a slug of the reaction mixture that travels through the flow reactor. The slug is initially confined with pure solvent at the start (head) and end (tail). A visual observation during these experiments is that the collected volume is significantly larger, 2-5 times, than the initial injection. As the reaction mixture is in contact with pure solvent at the head and tail, the concentration difference causes the solutes to diffuse into the pure solvent over time. This phenomenon is dependent on the diffusion coefficient, which is proportional to the temperature and inversely proportional to the viscosity of the reaction mixture. As the viscosity itself is inversely proportional to the temperature, the diffusion effect will further increase with increasing temperature. Diffusion is therefore suspected to reduce the effective concentration of the reactant solution close to the head and tail of the injection, leading to a decrease in reaction rate, which results in shorter polymer chains. This effect can explain the increase of the volume of the reaction mixture and the decrease of the average molecular weight with increasing temperature. The effective influence of diffusion can be investigated in more detail by performing studies on the injected volume and concentration of the reaction mixture.

\section{Residence time and injection volume}

The residence time experiments were divided in 3 different series based on the scale of the injection volume, i.e. 1.75, 4.5 , and $9 \mathrm{~mL}$ for the first, second, and third series, respectively (Table 3). This 
volume difference was implemented to evaluate the effect of forward and backward diffusion on the polymer molecular weight. For the first series (entries 1a-b), extending the residence time to 60 minutes did not show a significant increase of the molecular weight, indicating that 30 minutes is sufficient to reach the experimental end stage of the flow polymerization. For the second series, the residence time was shortened to 20,10, and 5 minutes (entries 2a-c), whereas in the third series, 15 and 20 minutes were compared (entries 3a-b). Overall, no major changes in the molecular weight were observed unless the residence time was reduced to 5 minutes (entry $2 \mathrm{c}$ ). These results suggest that the initial polymerization rate of the Stille cross-coupling in flow is high and shortly after the reaction mixture enters the reactor, conjugated polymer chains of moderate length are already formed. This effect can also be visually observed as the reaction mixture changes from orange/reddish to deep purple within centimetres upon entering the reactor (Figure S1, S2). This initial fast rate was also observed in the batch experiments, but on a different time scale, as within 5 minutes an average molecular weight of $43.8 \mathrm{kDa}$ is reached in flow (entry $2 \mathrm{c}$ ), compared to $35 \mathrm{kDa}$ after 1 hour in batch (vide supra).

Table 3: Number-average molecular weights of the PffBT4T-2OD polymers synthesized in flow at different projected residence times and injection volumes. ${ }^{\mathrm{a}}$

\begin{tabular}{c|c|c|c|c}
\hline Entry & $\boldsymbol{t}_{\mathbf{r}}(\mathbf{m i n})$ & $\begin{array}{c}\text { Injected } \\
\text { volume }(\mathbf{m L} \mathbf{L})\end{array}$ & $\boldsymbol{M}_{\mathbf{n}}(\mathbf{k D a})$ & $\boldsymbol{\Xi}$ \\
\hline 1a & 30 & 1.75 & 48.6 & 2.1 \\
1b & 60 & 1.75 & 47.7 & 2.1 \\
2a & 20 & 4.5 & 47.8 & 2.1 \\
2b & 10 & 4.5 & 47.8 & 2.1 \\
2c & 5 & 4.5 & 43.8 & 2.1 \\
3a & 20 & 9 & 51.7 & 2.0 \\
3b & 15 & 9 & 50.9 & 2.1 \\
4 & 26 & 18 & 54.9 & 2.0 \\
\hline
\end{tabular}

a A residence time of 5, 10, 15, 20, 26, 30, and 60 minutes correlates with a set overall flow rate of 4000, 2000, 1332, 1000, 754,666 , and $333 \mu \mathrm{L} / \mathrm{min}$, respectively. A constant monomer concentration of $59.2 \mathrm{mM}$ and a temperature of $120{ }^{\circ} \mathrm{C}$ were used.

The flow experiments at different reactor temperatures are fully consistent with the notion that the polymerization is significantly influenced by the phenomenon of forward and backward diffusion. The contact area with pure solvent, which is the actual location where diffusion takes place, only exists at the head and tail of the injection slug and is determined by the cross-sectional area of the tubing. Increasing the injection volume increases the length scale of the reaction mixture slug as the crosssection remains constant. Therefore, the absolute amount of diffusion that takes place is irrespective of the injection volume. On the contrary, the relative percentage of diffusion with respect to the reaction mixture decreases when the injection volume becomes bigger, and the influence of the diffused part on the number-average molecular weight of the polymer should diminish. This effect is clearly visible from the data in Table 3, as the molecular weight increases when the injection volume is doubled (entry $2 \mathrm{a}$ vs. 3a). The strongest increase can be observed by comparison of the smallest (entry 1a) and largest (entry 4) injection size, even though the residence time is slightly shorter.

While screening for conditions, the injection size has to be chosen sufficiently large to cause the diffusion effect to be almost negligible. Otherwise, the conversion of the reaction, in this case correlated with the molecular weight, with respect to the upscaling will differ too much. For PffBT4T2OD, slight alterations in the molecular weight cause a large fluctuation in the solubility of the material and thereby drastically change its processability, which in turn leads to notable changes in the PCEs of the photovoltaic devices. When scalability is defined as the transformation from single 
injection to continuous operation, a flow protocol is only scalable when the relative percentage of forward and backward diffusion is negligibly small. Without resource limitations or with a direct aim for synthesizing larger quantities, initial screening can, however, directly be done under continuous operation instead of using injections and therefor there will be no diffusion effect as there is no head or tail front at which it can happen.

\section{Concentration}

From the previous experiments it can be concluded that it is difficult to control the molecular weight of the final polymer only with residence time. The polymerization rate is highly dependent on the reactive group concentration. Therefore, a concentration screening was performed, using 100, 66, and $33 \%$ of the standard concentration used so far, allowing a material production rate of 1.2, 0.8, and 0.4 $\mathrm{g}$ per hour, respectively. In order to minimize the influence of diffusion, the injected volume was chosen to be sufficiently large $(18 \mathrm{~mL})$. Table 4 shows that effective reduction of the molecular weight can indeed be achieved by lowering the concentration. The molecular weights of the first two experiments (entries 1 and 2) are close to those of the second and first commercial polymer samples, respectively. The concentration is hence a key parameter in efficient processes utilizing flow technology to prepare PffBT4T-2OD polymers with narrow control over the molecular weight. The availability of different molecular weights provides additional opportunities to tune the active layer morphology and the donor-acceptor interactions inside the BHJ layer of OPV devices. This can be particularly interesting when combining PffBT4T-2OD with novel promising non-fullerene acceptors. ${ }^{7-11}$ Their solubility can differentiate strongly from the conventionally used fullerene acceptors, which can cause problems in obtaining the desired morphology.

Table 4: Number-average molecular weights of the PffBT4T-2OD polymers synthesized in flow at different injection concentrations. $^{\text {a }}$

\begin{tabular}{c|c|c|c}
\hline Entry & $\begin{array}{c}\text { Monomer } \\
\text { concentration }(\mathbf{m M})\end{array}$ & $\begin{array}{c}\boldsymbol{M}_{\mathbf{n}} \\
(\mathbf{k D a})\end{array}$ & $\boldsymbol{Ð}$ \\
\hline 1 & 59.2 & 54.9 & 2.0 \\
2 & 39.5 & 43.9 & 2.0 \\
3 & 19.7 & 26.6 & 1.8 \\
\hline
\end{tabular}

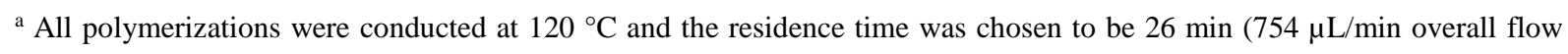
rate).

\subsubsection{Synthesis of PffBT4T-2DT}

As a higher molecular weight can be beneficial for certain optoelectronic properties, including charge mobility, but causes severe processing issues for PffBT4T-2OD, we carried out the flow synthesis of a polymer with an analogous backbone, i.e. PffBT4T-2DT (Scheme 1). ${ }^{61,62}$ For similar molecular weights, the PffBT4T-2DT polymer should have a higher solubility, and therefore processability, than PffBT4T-2OD because of the increased side chain length. The flow conditions which resulted in a number-average molecular weight of $54.9 \mathrm{kDa}$ for PffBT4T-2OD were used for comparative reasons $\left(t_{\mathrm{r}}=26 \mathrm{~min}, T=120^{\circ} \mathrm{C},[\mathrm{M}]=59.2 \mathrm{mM}, V_{\text {inj }}=18 \mathrm{~mL}\right.$; Table 3, entry 4). A similar molecular weight $\left(M_{\mathrm{n}}=56.1 \mathrm{kDa}\right)$ was achieved, indicating that the degree of polymerization is similar for both polymers. In general, molecular weights of PffBT4T-2DT synthesized under the same flow conditions as PffBT4T-2OD can be slightly higher due to the $\pm 10 \%$ difference in molecular weight of the polymer repeat unit. 


\subsection{Photovoltaic properties}

Similar to the commercial samples, the material quality of the synthesized flow polymers was evaluated by their application in BHJ OPV devices ( $I-V$ figures in ESI). Devices were fabricated with the same protocol, with a polymer concentration of $7.5 \mathrm{mg} / \mathrm{mL}$. Two samples from the concentration experiment, employing large injection volumes, were used as these conditions can readily be employed for continuous production and their molecular weight approaches the values of the commercial samples (Table 5, entry 3 and 4). Additionally, one small-scale injection volume sample with a molecular weight of $41.8 \mathrm{kDa}$ was used, as it approaches the molecular weight of the commercial sample from the first supplier $(41.8 \mathrm{kDa})$ more closely, although the difference is within the experimental GPC error (Table 5, entry 5). The PffBT4T-2OD high molecular weight commercial sample (Table 5, entry 2) and its flow-synthesized equivalent (Table 5, entry 3 ) display a similar photovoltaic performance, although the commercial material has a higher maximum PCE value. We attribute the large difference between the average and maximum PCE to the higher molecular weight of the polymer, resulting in a lower device reproducibility due to the increased difficulty in processing these materials. The PffBT4T-2OD lower molecular weight commercial sample (Table 5, entry 1) and both of its large- and small-scale flow-synthesized equivalents (Table 5, entry 4 and 5) also display a similar photovoltaic performance, with maximum values reaching the threshold of $10 \%$. From these results it can be concluded that continuous flow is capable of synthesizing high quality PffBT4T-2OD material, which performs equally well in BHJ solar cells as the commercially available PffBT4T-2OD, with the additional advantage that the production of larger quantities of material is straightforward.

Finally, the analogous PffBT4T-2DT material was tested for its photovoltaic performance. As outlined before, this material has a higher solubility than the traditional PffBT4T-2OD and is therefore easier to handle in device fabrication. To our knowledge, the highest reported efficiency for this material in combination with $\mathrm{PC}_{71} \mathrm{BM}$ is $7.6 \% .^{61}$ The significantly higher PCE of the flow-synthesized material in this study (9.4\%; Table 5, entry 6) is likely due to the higher molecular weight (56.1 vs $46.4 \mathrm{kDa})$. In the OPV field, alternative acceptors to replace the rather expensive fullerenes are currently being investigated intensively. The PffBT4T-2DT analogue has already been shown to reach an efficiency of $9.95 \%$ in combination with the alternative acceptor IDTBR, confirming the high potential of this material. ${ }^{9}$

Table 5: Photovoltaic performances of the BHJ polymer solar cells employing PffBT4T-2OD or PffBT4T-2DT from commercial sources or produced by continuous flow chemistry (in combination with $\mathrm{PC}_{71} \mathrm{BM}$ in a 1:1.2 (wt/wt\%) ratio; spincoating from 1:1 (vol/vol\%) chlorobenzene-dichlorobenzene $+3 \%$ diiodooctane).

\begin{tabular}{c|c|c|c|c|c|c}
\hline Entry & Polymer & $\boldsymbol{M}_{\mathbf{n}}(\mathbf{k D a})$ & $\boldsymbol{J}_{\mathbf{s c}}\left(\mathbf{m A} / \mathbf{c m}^{2}\right)$ & $\boldsymbol{V}_{\mathbf{o c}}(\mathbf{V})$ & $\mathbf{F F}(\boldsymbol{\%})$ & $\mathbf{P C E}_{(\%)}$ \\
\hline 1 & PffBT4T-2OD (Supplier 1) & 41.8 & 18.6 & 0.74 & 68 & $9.8(10.1)$ \\
2 & PffBT4T-2OD (Supplier 2) & 57.2 & 18.3 & 0.73 & 64 & $8.4(9.9)$ \\
\hline 3 & PffBT4T-2OD & 54.9 & 18.7 & 0.72 & 66 & $8.8(9.0)$ \\
4 & PffBT4T-2OD & 43.9 & 18.8 & 0.72 & 68 & $9.3(9.8)$ \\
5 & PffBT4T-2OD & 41.8 & 20.8 & 0.72 & 62 & $9.4(10.1)$ \\
\hline 6 & PffBT4T-2DT & 56.1 & 19.4 & 0.74 & 64 & $9.4(9.8)$ \\
\hline
\end{tabular}

${ }^{a}$ Averages over at least 8 devices; values in parentheses are maximum efficiencies.

\section{Conclusions}

In this work, two prototype OPV donor polymers, PffBT4T-2OD and PffBT4T-2DT, were successfully synthesized via continuous flow chemistry, which allows reproducible production of device-quality materials. Through careful selection of the flow conditions, specific molecular weights were targeted and attained. The influence of reaction temperature, residence time, injection volume, and concentration on the final molecular weight of the PffBT4T-2OD polymer was investigated. When 
using injections to screen the flow conditions, diffusion was found to play a major role and its influence on small-scale reactions cannot be neglected. High molecular weight PffBT4T-2OD (54.9 $\mathrm{kDa}$ ) can be produced via flow at a rate of $1.2 \mathrm{~g}$ /hour, affording polymer solar cells with an efficiency up to $9.0 \%$, while somewhat lower molecular weight PffBT4T-2OD can be produced at a rate of 0.8 $\mathrm{g} /$ hour, affording devices with efficiencies up to $9.8 \%$. Although the production rate of the lower molecular weight polymer is slightly lower, it was found to be significantly easier to be processed into BHJ solar cell devices. It therefore may have advantages for use in R2R printing processes. Along with PffBT4T-2OD, the PffBT4T-2DT analogue was also successfully synthesized by flow, affording OPV devices with efficiencies up to $9.8 \%$. The synthesized PffBT4T-2DT polymer exhibits an improved ease of processing, even relative to the lower molecular weight PffBT4T-2OD batch, and may not only be suitable for R2R processing, but also opens up a window of opportunities for combinations with emerging alternative acceptor materials.

\section{Experimental section}

\subsection{Materials and methods}

All reagents and chemicals were obtained from commercial sources and used without further purification. Silver pivalate, ${ }^{63} \quad$ 2-bromo-3-(2-decyltetradecyl)thiophene, ${ }^{64}$ 2-bromo-3-(2octyldodecyl)thiophene, ${ }^{3}$ and 5,6-difluoro-2,1,3-benzothiadiazole ${ }^{50}$ were synthesized according to literature procedures. Commercial samples of PffBT4T-2OD were purchased from 1-Material (supplier 1) and Solarmer (supplier 2).

${ }^{1} \mathrm{H}$ NMR spectra were acquired using a Bruker AMX-500 spectrometer and the signals were referenced to a residual solvent peak $\left(\delta 7.26 \mathrm{ppm}\right.$ for $\mathrm{CHCl}_{3}$ and $\delta 6.00 \mathrm{ppm}$ for 1,1,2,2tetrachloroethane) or the internal standard TMS $(\delta 0.0 \mathrm{ppm}) .{ }^{19} \mathrm{~F}$ NMR spectra $(470 \mathrm{MHz})$ were recorded using trifluorotoluene as an external standard $(\delta-63.73 \mathrm{ppm})$. Chromatographic separations were performed by standard flash column chromatography methods using silica gel purchased from Sorbent Technologies ( $60 \AA$, 32-63 $\mu \mathrm{m}$ ). Molecular weights and dispersities were determined by GPC using an EcoSEC High Temperature GPC system HLC-8321GPC/HT with RI detector manufactured by Tosoh Bioscience. Experiments were carried out with 1,2,4-trichlorobenzene as the eluent at a flow rate of $1 \mathrm{~mL} / \mathrm{min}$ at $140{ }^{\circ} \mathrm{C}$ on two $7.8 \mathrm{~mm} \times 30 \mathrm{~cm}, 13 \mu \mathrm{m}$ TSK-Gel GMH $\mathrm{HR}_{\mathrm{HR}} \mathrm{H}(\mathrm{S}) \mathrm{HT} 2$ columns in series (Tosoh Bioscience). The instrument was calibrated using polystyrene standards (4,930-1,214,000 g/mol) and the data were analysed using 8321GPC-WS Analysis software. To prepare the polymer samples for the GPC measurements, the polymer was wrapped in stainless steel mesh $\left(96 \mu \mathrm{m}\right.$ pore size, Tosoh Bioscience) and heated in 1,2,4-trichlorobenzene at $120{ }^{\circ} \mathrm{C}$ for $3 \mathrm{~h}$ to afford a solution of $1.0 \mathrm{mg} / \mathrm{mL}$. The resulting solution was transferred to a sample vial for injection.

All flow experiments were conducted on a home-made continuous flow apparatus (Figure 1, S1, S2). The system is comprised of a KDS-200 Legacy syringe pump (1) used for the injection of the reaction mixture, an ISCO 260D high pressure syringe pump system (2) for pushing the reaction mixture through the reactor, a perfluoroalkoxy (PFA) tubular reactor of $20 \mathrm{~mL}$ (3) immersed in a heated oil bath, an Eldex Optos model 1 high pressure liquid metering pump (4) for in-line dilution, and a 4-way valve (5) to establish the injection. The entire flow system was pressurized outside the heating compartment with a back pressure regulator (BPR) of 40 psi from Upchurch Scientific. After the initial set-up of the system, all pumps, connection lines, valves, and the flow reactor itself were flushed with acetone, anhydrous toluene, and finally with degassed chlorobenzene to assure an inert atmosphere inside the flow reactor. The entire flow system was stored under chlorobenzene in between experiments and was flushed with freshly degassed chlorobenzene before every injection series. All 
reported reaction temperatures were allowed to equilibrate for a least $30 \mathrm{~min}$ before the actual experiment started.

\subsection{Monomer synthesis}

\section{4,7-Bis[5-bromo-4-(2-octyldodecyl)thiophen-2-yl]-5,6-difluorobenzo $[c][1,2,5]$ thiadiazole $(1 \mathrm{a})^{3}$}

5,6-Difluoro-2,1,3-benzothiadiazole ${ }^{50}$ (172 mg, $\left.1 \mathrm{mmol}\right), 2$-bromo-3-(2-octyldodecyl)thiophene ${ }^{3}$ (1.76 $\mathrm{g}, 4 \mathrm{mmol}), \mathrm{Pd}(\mathrm{OAc})_{2}(22.4 \mathrm{mg}, 0.1 \mathrm{mmol})$, and silver pivalate $(1.68 \mathrm{~g}, 8 \mathrm{mmol})$ were added sequentially to a collared tube (CEM Corp., Prod \# 89079-404) with a magnetic stirring bar. The tube was crimp-sealed with a septum-cap inside a glove box. DMSO $(5 \mathrm{~mL})$ was added and the reaction mixture was heated in a $80{ }^{\circ} \mathrm{C}$ aluminum block. After $20 \mathrm{~h}$, the reaction mixture was cooled to room temperature, diluted with $\mathrm{CH}_{2} \mathrm{Cl}_{2}(100 \mathrm{~mL})$, and filtered through Celite ${ }^{\circledR}(10 \mathrm{~mL})$. The filtrate was concentrated under reduced pressure. The resulting residue was purified by silica gel chromatography (200 $\mathrm{mL}$ of silica gel, hexanes as eluent), followed by precipitation in dichloromethane/methanol to yield the product as an orange solid (715 $\mathrm{mg}, 68 \%) .{ }^{1} \mathrm{H} \mathrm{NMR}\left(400 \mathrm{MHz}, \mathrm{CDCl}_{3}\right) \delta 7.97(\mathrm{~s}, 2 \mathrm{H}), 2.59$ $(\mathrm{d}, J=7.2 \mathrm{~Hz}, 4 \mathrm{H}), 1.80-1.60(\mathrm{~m}, 2 \mathrm{H}), 1.35-1.20(\mathrm{~m}, 64 \mathrm{H}), 0.90-0.60(\mathrm{~m}, 12 \mathrm{H}) .{ }^{19} \mathrm{~F}$ NMR $(470 \mathrm{MHz}$, $\left.\mathrm{CDCl}_{3}\right) \delta-129.41$.

\section{4,7-Bis[5-bromo-4-(2-decyltetradecyl)thiophen-2-yl]-5,6-difluorobenzo[c] $[1,2,5]$ thiadiazole $(1 \mathrm{~b})^{61}$}

5,6-Difluoro-2,1,3-benzothiadiazole ${ }^{50}(172 \mathrm{mg}, 1 \mathrm{mmol})$, 2-bromo-3-(2-decyltetradecyl)thiophene ${ }^{64}$ $(2.00 \mathrm{~g}, 4 \mathrm{mmol}), \mathrm{Pd}(\mathrm{OAc})_{2}(22.4 \mathrm{mg}, 0.1 \mathrm{mmol})$, and silver pivalate $(1.68 \mathrm{~g}, 8 \mathrm{mmol})$ were added sequentially to a collared tube (CEM Corp., Prod \# 89079-404) with a magnetic stirring bar. The tube was crimp-sealed with a septum-cap inside a glove box. DMSO $(5 \mathrm{~mL})$ was added and the reaction mixture was heated in a $80{ }^{\circ} \mathrm{C}$ aluminum block. After $20 \mathrm{~h}$, the reaction mixture was cooled to room temperature, diluted with dichloromethane $(100 \mathrm{~mL})$, and filtered through Celite ${ }^{\circledR}(10 \mathrm{~mL})$. The filtrate was concentrated under reduced pressure. The resulting residue was purified by silica gel chromatography (200 mL of silica gel, hexanes as eluent), followed by precipitation in dichloromethane/methanol to yield the product as an orange solid (700 mg, 60\%). ${ }^{1} \mathrm{H}$ NMR $(500 \mathrm{MHz}$, $\left.\mathrm{CDCl}_{3}\right) \delta 7.97(\mathrm{~s}, 2 \mathrm{H}), 2.62(\mathrm{~d}, J=7.2 \mathrm{~Hz}, 4 \mathrm{H}), 1.80-1.60(\mathrm{~m}, 2 \mathrm{H}), 1.33-1.20(\mathrm{~m}, 80 \mathrm{H}), 1.00-0.80(\mathrm{~m}$, 12H). ${ }^{19} \mathrm{~F} \mathrm{NMR}\left(470 \mathrm{MHz}, \mathrm{CDCl}_{3}\right) \delta-128.12$.

\subsection{Typical procedure for the batch polymerization}

A microwave reaction tube equipped with a magnetic stirring bar was charged with 4,7-bis[5-bromo4-(2-octyldodecyl)thiophen-2-yl]-5,6-difluorobenzo[c][1,2,5]thiadiazole $(50.0 \mathrm{mg}, 0.047 \mathrm{mmol}$ ) and 5,5'-bis(trimethylstannyl)-2,2'-bithiophene $(23.3 \mathrm{mg}, 0.047 \mathrm{mmol})$. The reaction tube was transferred into a glove box before the addition of $\mathrm{Pd}_{2}(\mathrm{dba})_{3} \cdot \mathrm{CHCl}_{3}(0.25 \mathrm{mg}, 0.5 \mathrm{~mol} \%), \mathrm{P}(o \text {-tol })_{3}(0.5 \mathrm{mg}, 3.5$ mol\%) and freshly degassed chlorobenzene $(0.25 \mathrm{~mL})$. Afterwards, the tube was sealed in the glove box and transferred out to be immersed into an oil bath preheated to $145{ }^{\circ} \mathrm{C}$. The reaction mixture turned from dark red to viscous deep purple within $10 \mathrm{~min}$. The polymerization reaction was carried out for the designated reaction time (see Table 1) before being cooled to $100{ }^{\circ} \mathrm{C}$ or less, and opened up to air. ${ }^{*}$ Excess amount of the Pd scavenger diethylammonium diethyldithiocarbamate was added in approximately $5 \mathrm{~mL}$ of toluene. The mixture was then stirred at $80-100{ }^{\circ} \mathrm{C}$ for $1 \mathrm{~h}$ before it was precipitated in methanol $(100 \mathrm{~mL})$. The precipitates were filtered into an extraction thimble and the polymer was purified by successive soxhlet extractions with methanol, acetone, hexanes, dichloromethane, and chloroform. Finally, the product was collected with chlorobenzene. The solution

\footnotetext{
* For entry 5 of Table 1 , a second portion of the catalyst $\mathrm{Pd}_{2}(\mathrm{dba})_{3} / \mathrm{P}(o \text {-tol })_{3}(0.25 \mathrm{~mol} \%)$ in degassed chlorobenzene was added to the reaction mixture via syringe after the mixture was heated under stirring for $15 \mathrm{~min}$.
} 
was concentrated under reduced pressure and the polymer was precipitated again in methanol (100 $\mathrm{mL}$ ). The solids were collected by vacuum filtration and dried under vacuum to yield the polymer as a dark green solid.

\subsection{General procedure for the flow polymerization}

A vial equipped with a magnetic stirring bar was charged with a 1:1 ratio of 4,7-bis[5-bromo-4-(2octyldodecyl)thiophen-2-yl]-5,6-difluorobenzo[c][1,2,5]thiadiazole and 5,5'-bis(trimethylstannyl)-2,2'bithiophene, while a second vial was charged with $3 \mathrm{~mol} \% \mathrm{Pd}_{2}(\mathrm{dba})_{3}$ and $12 \mathrm{~mol} \% \mathrm{P}(o-\text { tol })_{3} \cdot{ }^{31}$ Both vials were flushed with nitrogen and transferred into a glovebox. Equal amounts of freshly degassed chlorobenzene were added and the solutions were stirred for 10-15 min. Two SGE gastight syringes (maximum volume of $10 \mathrm{~mL}$ ) were charged with the solutions and transferred outside the glovebox. The syringes were placed onto the KDS-200 Legacy syringe pump and rapidly connected to the system by a luer lock mechanism. Immediately after connection, the line connecting the syringes with the 4-way valve was flushed with a small amount of the reaction mixture to retain an inert atmosphere (as much as possible) within the flow system. The two injection streams were mixed in a T-piece mixer before entering the reactor. The reaction stream was diluted with chlorobenzene 1:1 right before exiting the reactor. An excess amount of the Pd scavenger diethylammonium diethyldithiocarbamate was added to the dilution stream. The polymer was collected by precipitation in methanol. Further purification was done by successive soxhlet extractions with methanol, hexanes, and dichloromethane and the product was finally collected with chlorobenzene. Re-precipitation of the product in methanol and vacuum filtration finally yielded the polymer as a dark green solid.

\subsection{OPV device fabrication}

An inverted bulk heterojunction solar cell architecture comprising of glass/ITO/ZnO/PffBT4T:PC ${ }_{71} \mathrm{BM} / \mathrm{MoO}_{3} / \mathrm{Ag}$ was used. Before device processing, the ITO-coated substrates (Tinwell Technology Ltd, Sheet resistance $15 \Omega /$ sq) were cleaned by sonicating with soap solution, DI water, acetone and isopropanol, followed by a $\mathrm{UV}^{-\mathrm{O}_{3}}$ treatment for $10 \mathrm{~min}$. The $\mathrm{ZnO}$ electron transport layer was deposited on the cleaned ITO substrates using spin-coating in ambient atmosphere to get a layer thickness of $\sim 30 \mathrm{~nm}$. After spin-coating, the $\mathrm{ZnO}$ layer was annealed in air at $150{ }^{\circ} \mathrm{C}$ for $10 \mathrm{~min}$ followed by slow cooling to room temperature. The $\mathrm{ZnO}$ solution used for spincoating was prepared using a standard procedure, i.e. employing a 1:1 molar ratio of zinc acetate and ethanolamine in 2-methoxyethanol as solvent. The photoactive layer solution was prepared by dissolving PffBT4T-2OD or PffBT4T-2DT and $\mathrm{PC}_{71} \mathrm{BM}$ in the solvent mixture chlorobenzene:1,2dichlorobenzene (1:1 vol ratio) with $3 \%$ DIO as additive. The ratio of polymer:fullerene used was $1: 1.2(\mathrm{wt} / \mathrm{wt}$ ) with a polymer concentration of $7.5 \mathrm{mg} / \mathrm{mL}$ for all samples, except for the commercial sample from the second supplier (provided protocol). The solution was stirred at $110{ }^{\circ} \mathrm{C}$ for $2 \mathrm{~h}$ to ensure proper dissolution. The active layer was coated on top of the $\mathrm{ZnO}$ layer in an Ar glove box at 600 r.p.m. to obtain thicknesses of $\sim 300 \mathrm{~nm}$. Prior to spin-coating, both the polymer solution and the ITO substrate were preheated on a hot plate at $110^{\circ} \mathrm{C}$. Active layers were spin-coated from the warm polymer solutions on the preheated substrates in an Ar glovebox. To remove the additive from the photoactive layer, the samples were placed in a vacuum chamber with a pressure of $1 \times 10^{-5} \mathrm{mbar}$ for $45 \mathrm{~min}$. The top electrodes, $\mathrm{MoO}_{3}$ and $\mathrm{Ag}$, were deposited by vacuum deposition with layer thicknesses of 20 and $160 \mathrm{~nm}$, respectively, to obtain complete solar cell devices with an active area of $0.08 \mathrm{~cm}^{2}$, defined by a metal mask with an aperture aligned with the device area. The $I-V$ characteristics of all photovoltaic devices were evaluated under AM 1.5G solar illumination (100 $\mathrm{mW} / \mathrm{cm}^{2}$ ) using a Keithley 4200 semiconductor parameter analyzer system with a Newport Thermal Oriel 94021 solar simulator calibrated with a reference silicon solar cell. 


\section{Acknowledgements}

The authors of the Georgia Institute of Technology thank the National Science Foundation for support through the CCI Center for Selective C-H Functionalization (CHE-1205646) and the Department of the Navy, Office of Naval Research for support through Award No. N00014-14-1-0580 (CAOP MURI). The Belgian co-authors thank Hasselt University for continuing financial support. This work is also supported by the IAP 7/05 project Functional Supramolecular Systems, granted by the Science Policy Office of the Belgian Federal Government (BELSPO). We are also grateful for financial support by the Research Foundation - Flanders (FWO) (projects G.0415.14N and G.0B67.15N). Most of the work was performed during the stay of G. Pirotte as a visiting researcher at Georgia Institute of Technology, funded by the FWO (V4.298.16N) and a personal grant from the District 1630 of Rotary International, supported by the Rotary Foundation.

\section{References}

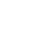

L. Dou, J. You, Z. Hong, Z. Xu, G. Li, R. A. Street and Y. Yang, Adv. Mater., 2013, 25, 6642-6671.

K. A. Mazzio and C. K. Luscombe, Chem. Soc. Rev., 2015, 44, 78-90.

Y. Liu, J. Zhao, Z. Li, C. Mu, W. Ma, H. Hu, K. Jiang, H. Lin, H. Ade and H. Yan, Nat. Commun., 2014, 5, 5293.

G. Li, R. Zhu and Y. Yang, Nat. Photonics, 2012, 6, 153-161.

L. K. Jagadamma, M. Al-Senani, A. El-Labban, I. Gereige, G. O. Ngongang Ndjawa, J. C. D. Faria, T. Kim, K. Zhao, F. Cruciani, D. H. Anjum, M. A. McLachlan, P. M. Beaujuge and A. Amassian, Adv. Energy Mater., 2015, 5, 1500204.

Z. He, B. Xiao, F. Liu, H. Wu, Y. Yang, S. Xiao, C. Wang, T. P. Russell and Y. Cao, Nat. Photonics, 2015, 9, 174-179.

Y. Lin, F. Zhao, Y. Wu, K. Chen, Y. Xia, G. Li, S. K. K. Prasad, J. Zhu, L. Huo, H. Bin, Z. G. Zhang, X. Guo, M. Zhang, Y. Sun, F. Gao, Z. Wei, W. Ma, C. Wang, J. Hodgkiss, Z. Bo, O. Inganäs, Y. Li and X. Zhan, Adv. Mater., 2016, 29, 1604155.

W. Zhao, D. Qian, S. Zhang, S. Li, O. Inganäs, F. Gao and J. Hou, Adv. Mater., 2016, 28, 4734-4739.

D. Baran, T. Kirchartz, S. Wheeler, S. Dimitrov, M. Abdelsamie, J. Gorman, R. Ashraf, S. Holliday, A. Wadsworth, N. Gasparini, P. Kaienburg, H. Yan, A. Amassian, C. J. Brabec, J. Durrant and I. McCulloch, Energy Environ. Sci., 2016, 9, 3783-3793. D. Meng, D. Sun, C. Zhong, T. Liu, B. Fan, L. Huo, Y. Li, W. Jiang, H. Choi, T. Kim, J. Y. Kim, Y. Sun, Z. Wang and A. J. Heeger, J. Am. Chem. Soc., 2016, 138, 375-380. S. Holliday, R. S. Ashraf, A. Wadsworth, D. Baran, S. A. Yousaf, C. B. Nielsen, C.-H. Tan, S. D. Dimitrov, Z. Shang, N. Gasparini, M. Alamoudi, F. Laquai, C. J. Brabec, A. Salleo, J. R. Durrant and I. McCulloch, Nat. Commun., 2016, 7, 11585.

F. C. Krebs, T. Tromholt and M. Jørgensen, Nanoscale, 2010, 2, 873-886.

M. Jørgensen, K. Norrman, S. A. Gevorgyan, T. Tromholt, B. Andreasen and F. C. Krebs, Adv. Mater., 2012, 24, 580-612.

K. Zhao, H. Hu, E. Spada, L. K. Jagadamma, B. Yan, M. Abdelsamie, Y. Yang, L. Yu, R. Munir, R. Li, G. O. N. Ndjawa and A. Amassian, J. Mater. Chem. A, 2016, 4, 16036-16046.

M. Helgesen, J. E. Carlé, G. A. dos Reis Benatto, R. R. Søndergaard, M. Jørgensen, E. Bundgaard and F. C. Krebs, Adv. Energy Mater., 2015, 5, 1401996. 
C. Wiles and P. Watts, Green Chem., 2012, 14, 38-54.

C. Wiles and P. Watts, Eur. J. Org. Chem., 2008, 1655-1671.

J. Wegner, S. Ceylan and A. Kirschning, Adv. Synth. Catal., 2012, 354, 17-57.

G. Jas and A. Kirschning, Chem. - A Eur. J., 2003, 9, 5708-5723.

P. Watts and S. J. Haswell, Chem. Soc. Rev., 2005, 34, 235-246.

S. G. Newman and K. F. Jensen, Green Chem., 2013, 15, 1456-1472.

P. Styring and A. I. R. Parracho, Beilstein J. Org. Chem., 2009, 5.

N. Jongen, M. Donnet, P. Bowen, J. Lemaître, H. Hofmann, R. Schenk, C. Hofmann, M. AounHabbache, S. Guillemet-Fritsch, J. Sarrias, A. Rousset, M. Viviani, M. T. Buscaglia, V. Buscaglia, P. Nanni, A. Testino and J. R. Herguijuela, Chem. Eng. Technol., 2003, 26, 303-305.

F. Ullah, T. Samarakoon, A. Rolfe, R. D. Kurtz, P. R. Hanson and M. G. Organ, Chem. Eur. J., 2010, 16, 10959-10962.

P. V. Snytnikov, D. I. Potemkin, E. V. Rebrov, V. A. Sobyanin, V. Hessel and J. C. Schouten, Chem. Eng. J., 2010, 160, 923-929.

J. D. Moseley and E. K. Woodman, Org. Process Res. Dev., 2008, 12, 967-981.

P. Löb, H. Löwe and V. Hessel, J. Fluor. Chem., 2004, 125, 1677-1694.

J. H. Bannock, S. H. Krishnadasan, A. M. Nightingale, C. P. Yau, K. Khaw, D. Burkitt, J. J. M. Halls, M. Heeney and J. C. De Mello, Adv. Funct. Mater., 2013, 23, 2123-2129.

H. Seyler, J. Subbiah, D. J. Jones, A. B. Holmes and W. W. H. Wong, Beilstein J. Org. Chem., 2013, 9, 1492-1500.

A. Kumar, J. Hasan, A. Majji, A. Avhale, S. Gopinathan, P. Sharma, D. Tarange, R. Bajpai and A. Kumar, J. Flow Chem., 2014, 4, 206-210.

G. Pirotte, J. Kesters, P. Verstappen, S. Govaerts, J. Manca, L. Lutsen, D. Vanderzande and W. Maes, ChemSusChem, 2015, 8, 3228-3233.

J. H. Bannock, W. Xu, T. Baïssas, M. Heeney and J. C. de Mello, Eur. Polym. J., 2016, 80, 240-246.

H. Seyler, D. J. Jones, A. B. Holmes and W. W. H. Wong, Chem. Commun., 2012, 48, 1598-1600.

F. Grenier, B. R. Aich, Y. Lai, M. Guérette, A. B. Holmes, Y. Tao, W. W. H. Wong and M. Leclerc, Chem. Mater., 2015, 27, 2137-2143.

C. Liu, K. Wang, X. Hu, Y. Yang, C.-H. Hsu, W. Zhang, S. Xiao, X. Gong and Y. Cao, ACS Appl. Mater. Interfaces, 2013, 5, 12163-12167.

P. Schilinsky, U. Asawapirom, U. Scherf, M. Biele and C. J. Brabec, Chem. Mater., 2005, 17, 21752180 .

E. Bundgaard and F. C. Krebs, Sol. Energy Mater. Sol. Cells, 2007, 91, 954-985.

T. Vangerven, P. Verstappen, J. Drijkoningen, W. Dierckx, S. Himmelberger, A. Salleo, D. Vanderzande, W. Maes and J. V. Manca, Chem. Mater., 2015, 27, 3726-3732.

39 D. Spoltore, T. Vangerven, P. Verstappen, F. Piersimoni, S. Bertho, K. Vandewal, N. Van Den Brande, M. Defour, B. Van Mele, A. De Sio, J. Parisi, L. Lutsen, D. Vanderzande, W. Maes and J. V. Manca, Org. Electron., 2015, 21, 160-170. 
Chem. Mater., 2016, 28, 3481-3487.

A. Zen, J. Pflaum, S. Hirschmann, W. Zhuang, F. Jaiser, U. Asawapirom, J. P. Rabe, U. Scherf and D. Neher, Adv. Funct. Mater., 2004, 14, 757-764.

J. J. Intemann, K. Yao, H. L. Yip, Y. X. Xu, Y. X. Li, P. W. Liang, F. Z. Ding, X. Li and A. K. Y. Jen, Chem. Mater., 2013, 25, 3188-3195.

R. J. Kline, M. D. McGehee, E. N. Kadnikova, J. Liu and J. M. J. Fréchet, Adv. Mater., 2003, 15, 15191522.

M. Tong, S. Cho, J. T. Rogers, K. Schmidt, B. B. Y. Hsu, D. Moses, R. C. Coffin, E. J. Kramer, G. C. Bazan and A. J. Heeger, Adv. Funct. Mater., 2010, 20, 3959-3965.

X. Zhao, H. Tang, D. Yang, H. Li, W. Xu, L. Yin and X. Yang, Chinese J. Chem., 2012, 30, 2052-2058.

J.-F. Chang, J. Clark, N. Zhao, H. Sirringhaus, D. W. Breiby, J. W. Andreasen, M. M. Nielsen, M. Giles, M. Heeney and I. McCulloch, Phys. Rev. B, 2006, 74, 115318.

H. W. Ro, J. M. Downing, S. Engmann, A. A. Herzing, D. M. DeLongchamp, L. J. Richter, S. Mukherjee, H. Ade, M. Abdelsamie, L. K. Jagadamma, A. Amassian, Y. Liu and H. Yan, Energy Environ. Sci., 2016, 9, 2835-2846.

J. S. Ha, K. H. Kim and D. H. Choi, J. Am. Chem. Soc., 2011, 133, 10364-10367.

J. Zhang, T. C. Parker, W. Chen, L. Williams, V. N. Khrustalev, E. V. Jucov, S. Barlow, T. V. Timofeeva and S. R. Marder, J. Org. Chem., 2016, 81, 360-370.

J. Zhang, W. Chen, A. J. Rojas, E. V. Jucov, T. V. Timofeeva, T. C. Parker, S. Barlow and S. R. Marder, J. Am. Chem. Soc., 2013, 135, 16376-16379.

H. Hu, K. Jiang, G. Yang, J. Liu, Z. Li, H. Lin, Y. Liu, J. Zhao, J. Zhang, F. Huang, Y. Qu, W. Ma and H. Yan, J. Am. Chem. Soc., 2015, 137, 14149-14157.

D. Alberico, M. E. Scott and M. Lautens, Chem. Rev., 2007, 107, 174-238.

A. Nitti, R. Po, G. Bianchi and D. Pasini, Molecules, 2016, 22, 21.

A. S. Dudnik, T. J. Aldrich, N. D. Eastham, R. P. H. Chang, A. Facchetti and T. J. Marks, J. Am. Chem. Soc., 2016, 138, 15699-15709.

W. Wu, H. Xin, C. Ge and X. Gao, Tetrahedron Lett., 2017, 58, 175-184.

C. S. Yeung and V. M. Dong, Chem. Rev., 2011, 111, 1215-1292.

R. Po, G. Bianchi, C. Carbonera and A. Pellegrino, Macromolecules, 2015, 48, 453-461.

P. Espinet and A. M. Echavarren, Angew. Chem. Int. Ed., 2004, 43, 4704-4734.

V. Farina and G. P. Roth, Adv. Met.-Org. Chem., 1996, 5, 1-53.

V. Farina, Pure Appl. Chem., 1996, 68, 73-78.

Z. Chen, P. Cai, J. Chen, X. Liu, L. Zhang, L. Lan, J. Peng, Y. Ma and Y. Cao, Adv. Mater., 2014, 26, 2586-2591.

M. Li, C. An, T. Marszalek, M. Baumgarten, H. Yan, K. Müllen and W. Pisula, Adv. Mater., 2016, 28, 9430-9438.

K. Endo and R. H. Grubbs, J. Am. Chem. Soc., 2011, 133, 8525-8527. 
